\title{
ОСОБЕННОСТИ КРИСТАЛЛОХИМИИ 4С И БС ПИРРОТИНА ИЗ КОВДОРСКОГО ЩЕЛОЧНОГО МАССИВА
}

\section{Паникоровский Т.Л., Пахомовский Я.А., Базай А.В.} ФИЦ КНЦ РАН

Сульфиды фоскорит-карбонатитового комплекса Ковдорского массива представлены, в основном, пирротином [1-5]. По химическому составу можно выделить 4 разновидности этого минерала (рис. 1): $\mathrm{Fe}_{7} \mathrm{~S}_{8}, \mathrm{Fe}_{9} \mathrm{~S}_{10}, \mathrm{Fe}_{11} \mathrm{~S}_{12}$ и $\mathrm{FeS},-$ из которых резко доминирует псевдогексагональный немагнитный пирротин $\mathrm{Fe}_{9} \mathrm{~S}_{10}$. В данной работе представлены данные (табл. 1) о кристаллической структуре пирротина-4С и двух разновидностей пирротина-5С \{соответственно, образцы 00-01 (1), 36-33 (2) и 00-51 (3) \}.

Таблица 1. Кристаллографические данные и параметры уточнения кристаллической структуры пирротина из Ковдорского массива.

\begin{tabular}{|c|c|c|c|}
\hline Образец & 1 & 2 & 3 \\
\hline Модификация & $4 \mathrm{C}$ & $5 \mathrm{C}$ & $5 \mathrm{C}$ \\
\hline Уточненная формула & $\mathrm{Fe}_{6.78} \mathrm{~S}_{8}$ & $\mathrm{Fe}_{8.91} \mathrm{Ni}_{0.25} \mathrm{~S}_{10}$ & $\mathrm{Fe}_{8.88} \mathrm{~S}_{10}$ \\
\hline Температура (K) & $100(2)$ & $100(2)$ & $100(2)$ \\
\hline Сингония & ромбическая & моноклинная & моноклинная \\
\hline Пространственная группа & $\operatorname{Imm} 2$ & $C 2$ & $P 2_{1}$ \\
\hline$a(\AA)$ & $22.678(4)$ & $11.8624(9)$ & $6.8477(5)$ \\
\hline$b(\AA)$ & $3.4131(5)$ & $6.8613(5)$ & $28.584(4)$ \\
\hline$c(\AA)$ & $5.9083(13)$ & $28.593(2)$ & $6.8518(5)$ \\
\hline$\alpha\left({ }^{\circ}\right)$ & 90 & 90 & 90 \\
\hline$\beta\left(^{\circ}\right)$ & 90 & $89.897(8)$ & $119.972(11)$ \\
\hline$\gamma\left({ }^{\circ}\right)$ & 90 & 90 & 90 \\
\hline Объем $\left(\AA^{3}\right)$ & $457.31(15)$ & $2327.3(3)$ & $1161.8(2)$ \\
\hline $\mathrm{Z}$ & 2 & 8 & 4 \\
\hline$\rho_{\text {calc }}\left(\mathrm{g} / \mathrm{cm}^{3}\right)$ & 4.611 & 4.755 & 4.668 \\
\hline$\mu\left(\mathrm{mm}^{1}\right)$ & 12.202 & 12.914 & 12.499 \\
\hline $\mathrm{F}(000)$ & 608.0 & 3190.0 & 1563.0 \\
\hline Размер кристалла $\left(\mathrm{mm}^{3}\right)$ & $0.15 \times 0.15 \times 0.15$ & $0.18 \times 0.18 \times 0.10$ & $0.12 \times 0.12 \times 0.12$ \\
\hline Интервалы углов $2 \Theta\left(^{\circ}\right)$ & $7.126-54.92$ & $5.7-61.33$ & $5.7-61.932$ \\
\hline Индексы $(h k l)$ & $\begin{array}{l}-29 \leq \mathrm{h} \leq 27 \\
-3 \leq \mathrm{k} \leq 4 \\
-4 \leq 1 \leq 7\end{array}$ & $\begin{array}{l}-15 \leq \mathrm{h} \leq 16 \\
-8 \leq \mathrm{k} \leq 9 \\
-40 \leq 1 \leq 23\end{array}$ & $\begin{array}{l}-9 \leq \mathrm{h} \leq 7 \\
-38 \leq \mathrm{k} \leq 32 \\
-9 \leq 1 \leq 9\end{array}$ \\
\hline Число рефлексов & 1018 & 5920 & 6471 \\
\hline Независимые рефлексы & 475 & 4494 & 4708 \\
\hline$R_{\text {int }}, R_{\text {sigma }}$ & $0.0171,0.0189$ & $0.0354,0.0397$ & $0.0278,0.0271$ \\
\hline Фактор формы F² & 1.202 & 1.074 & 1.125 \\
\hline 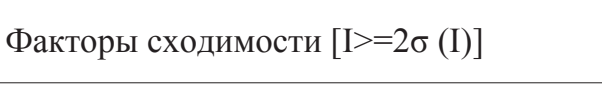 & $\begin{array}{l}R_{1}=0.0780 \\
\mathrm{w} R_{2}=0.1173\end{array}$ & $\begin{array}{l}R_{1}=0.0896, \\
\mathrm{w} R_{2}=0.2586\end{array}$ & $\begin{array}{l}R_{1}=0.0881, \\
\mathrm{w} R_{2}=0.1802\end{array}$ \\
\hline Факторы сходимости (по всем данным) & $\begin{array}{l}R_{1}=0.0817 \\
\mathrm{w} R_{2}=0.1197\end{array}$ & $\begin{array}{l}R_{1}=0.1009, \\
\mathrm{w} R_{2}=0.2728\end{array}$ & $\begin{array}{l}R_{1}=0.0990, \\
\mathrm{w} R_{2}=0.1874\end{array}$ \\
\hline$\rho_{\max }, \rho_{\min } \mathrm{e} \AA^{-3}$ & $1.61 /-2.06$ & $4.02 /-3.57$ & $4.93 /-4.66$ \\
\hline Параметр Flack & $0.49(12)$ & $0.53(19)$ & $0.09(6)$ \\
\hline
\end{tabular}

Массивы данных были получены на монокристальном дифрактометре Agilent Technologies Xcalibur Eos, оснащенного плоским CCD детектором, при комнатной температуре с использовани- 


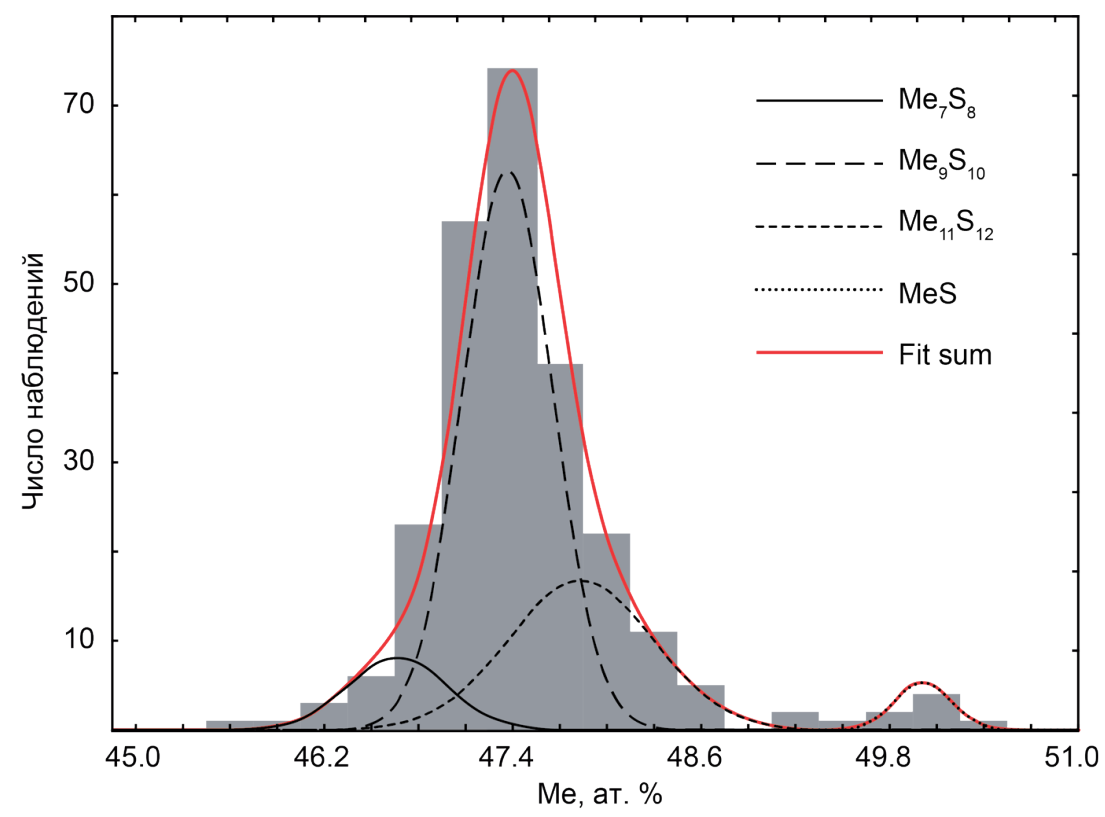

Рис. 1. Гистограмма суммарного содержания $\mathrm{Fe}, \mathrm{Ni}$ и Со в составе ковдорского пирротина.

ем монохроматического МоK $\alpha$ излучения $(\lambda=0.71069 \AA)$. Параметры элементарной ячейки уточнялись методом наименьших квадратов. Поправка на поглощение определена эмпирически с помощью сферических гармоник, реализованных в алгоритме калибрования SCALE ABSPACK, в программном комплексе CrysalysPro [6]. Уточнение структур проводилось с помощью программы SHELXL.
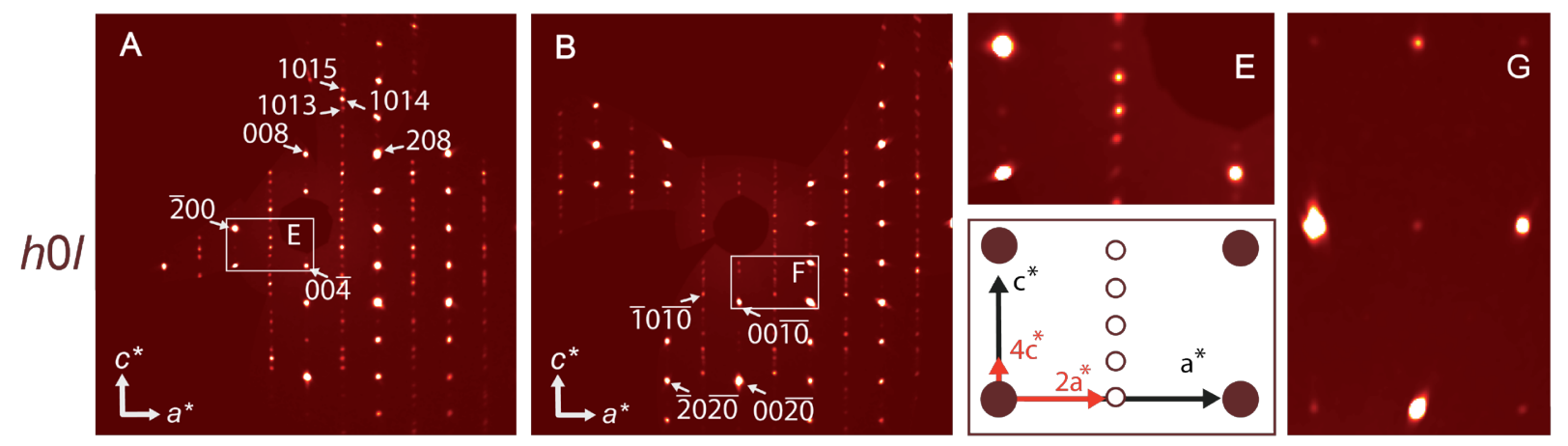

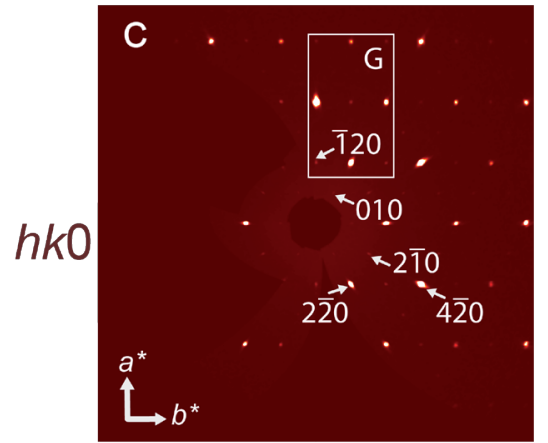

$4 \mathrm{C}$
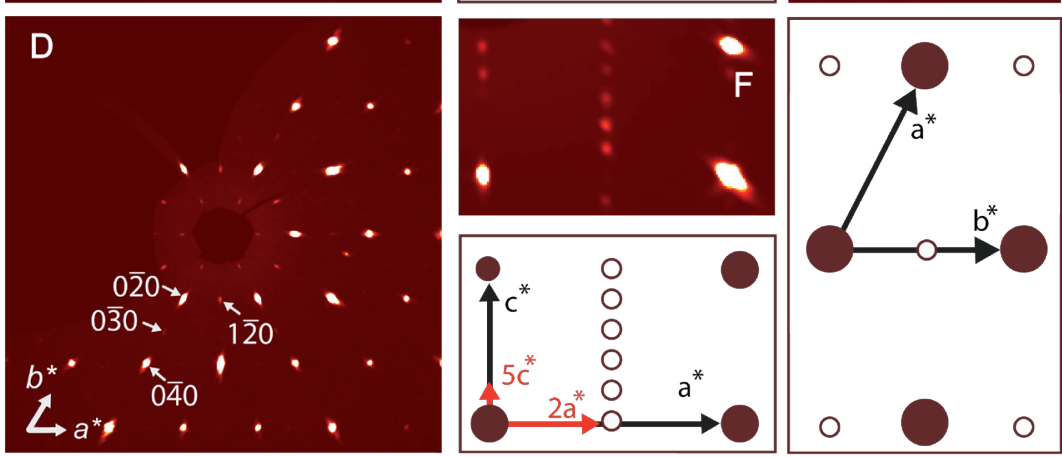

$5 \mathrm{C}$

Рис. 2. Реконструированное обратное пространство для $(h 0 l)$ и $(h k 0)$ сечений образцов $1(\mathrm{~A}, \mathrm{C})$ и $2(\mathrm{~B}, \mathrm{D})$ и его увеличенные фрагменты (E, F, G). Для образца 1 была использована матрица трансформации [010 001 100]. Белыми стрелками и цифрами показаны рефлексы и их индексы. Черным и красным цветом выделены векторы для обычной гексагональной ячейки и сверхструктуры, соответственно). Наиболее интенсивным рефлексам (тёмно-красные круги на схемах) соответствует гексагональная ячейка $(a=3.43, c=5.68 \AA$ ), сопутствующим низкоинтенсивным рефлексам (пустые кружки на схемах) - сверхячейка. 


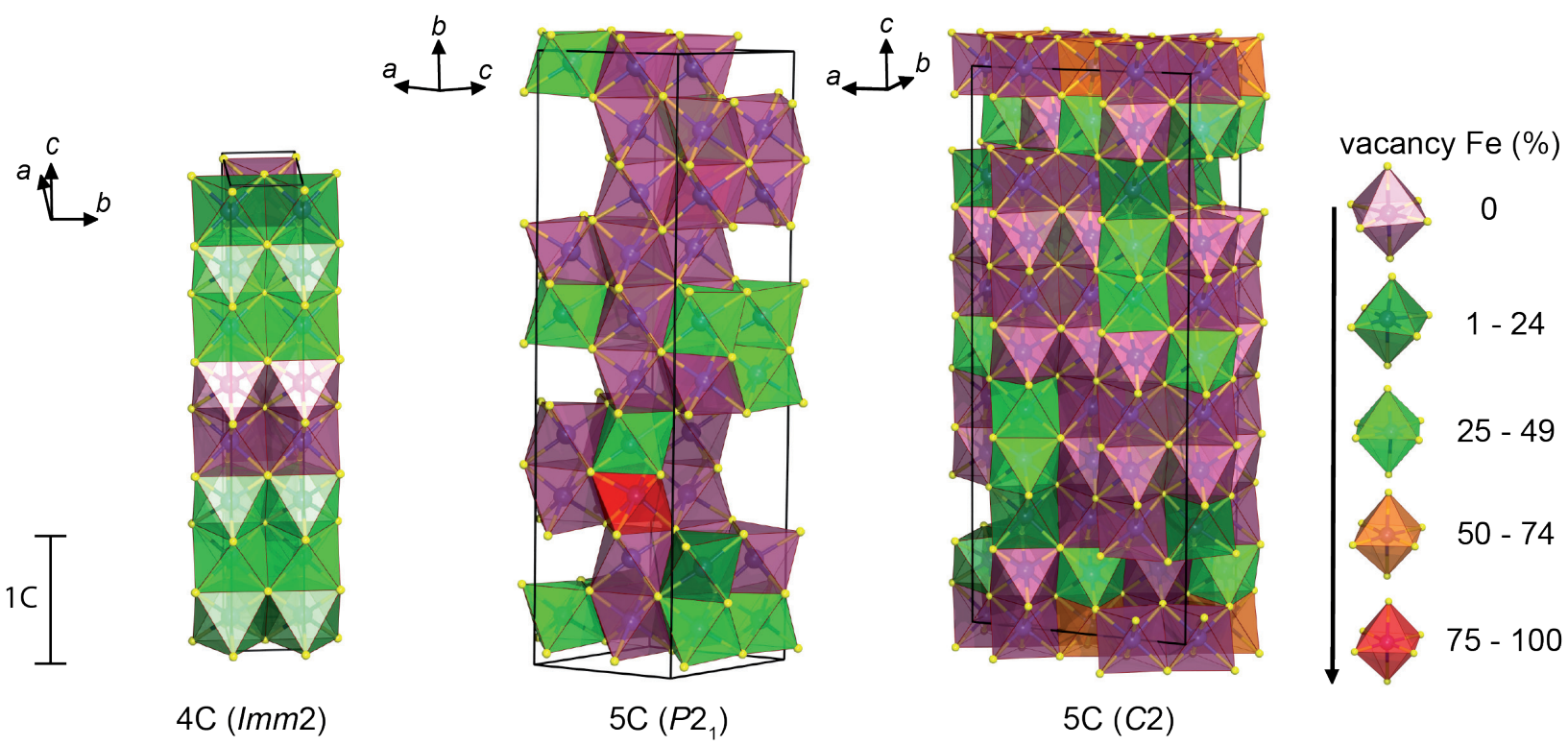

Рис. 3. Структурные модификации пирротина из Ковдорского щелочного массива (для 4С модификации была использована матрица трансформации [010 001 100]).

Структура пирротина была впервые расшифрована Нильсом Алсеном [7] в пространственной группе $P 6_{3} / m m c$ с параметрами ячейки $a=3.43$ и $c=5.68 \AA$. Она характеризуется двухслойной плотнейшей упаковкой, перпендикулярной оси с, в которой слои серы образуют слои А, B, а атомы железа занимают октаэдрические пустоты в этих слоях [8]. Упорядочение вакансий в позициях железа ведет к появлению дополнительных рефлексов из-за формирования сверхструктуры с моноклинной или ромбической симметрией (рис. 2). На данный момент в литературе описаны $4 C, 5 C$ и $6 C$ модификации пирротина, а также модулированные $N C$ структуры, где $N=4.88,5.5$ и т.д. [8]. Число $N$ обозначает кратность структуры вдоль параметра с относительно гексагональной ячейки и соответствует количеству дополнительных рефлексов в $(h 0 l)$ проекции обратного пространства, возникающих между интенсивными рефлексами гексагональной ячейки.

Кристаллическая структура $4 C$ модификации пирротина $\left(\mathrm{Fe}_{6.78} \mathrm{~S}_{8}\right)$, обладающего ферримагнитными свойствами, была уточнена в пространственной группе Imm2. Она отличается от преды-

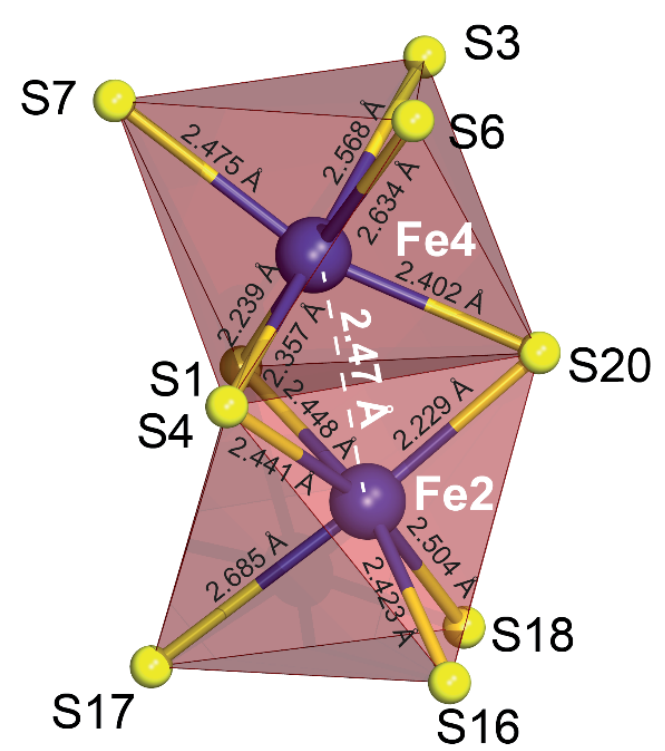

Рис. 4. Локальная координация $\mathrm{Fe} 2$ и $\mathrm{Fe} 4$ позиций в структуре образца 3 дущих расшифровок в пространственных группах $C 2 / c$ $\left(\mathrm{Fe}_{7} \mathrm{~S}_{8}\right)$ и $C 2[9]$ распределением вакансий в позициях $\mathrm{Fe}$ (рис. 3). В структуре пирротина- $4 C$ присутствуют 4 независимых позиции $\mathrm{Fe} 1, \mathrm{Fe} 2, \mathrm{Fe} 3, \mathrm{Fe} 4$, с уточнёнными заселённостями $0.89,0.75,1.00$ и 0.75 , соответственно.

В структуре пирротина-5С $\left(P 2_{1}\right)$ среди 20-ти независимых позиций железа, наблюдалась лишь одна (Fe2) позиция с низкой заселённостью <1/4. Дело в том, что позиции $\mathrm{Fe} 2$ и $\mathrm{Fe} 4$ (рис. 4) не могут иметь полную заселённость (их суммарная заселённость равняется 1.00) ввиду аномально короткого расстояния между ними в 2.470 А̊. Уточнённые заселённости для этих позиций составили 0.24 и 0.75 , соответственно. Аналогичный механизм распределения вакансий наблюдался для пирротина- $5 C$ $\left(P 2_{1}\right)$ в работе [10].

По нашим данным, большая часть пирротина в Ковдорском массиве относится к 5 С модификации, кристаллизующейся в пространственной группе $C 2$. Его уточнённый химический состав варьирует в пределах 
$\mathrm{Fe}_{8.84-8.99} \mathrm{~S}_{10}$, и в зависимости от этого меняется число вакансий в позициях железа. В структуре этой модификации наблюдалось от 6 до 9 частично вакантных позиций (из 22), заселённость которых варьируется в пределах 1-100\%. Такая вариативность структуры объясняет широкую распространённость данной модификации в Ковдорском комплексе. Наблюдаемые средние длинны связей Fе-О изменяются в узких пределах 2.426-2.454 А, что может означать частичное вхождение атомов $\mathrm{Fe}^{3+}$ в низкозаселенные позиции [7, 10].

Работа выполнена в рамках гранта РНФ 16-17-10173.

\section{Литература}

1. Иванюк Г.Ю., Яковенчук В.Н., Пахомовский Я.А. Ковдор. Апатиты: Минералы Лапландии. 2002.325 с.

2. Балабонин Н.Л., Волошин А.В., Пахомовский Я.А. Редкие сульфиды в породах Ковдорского массива // Минеральные комплексы и минералы Кольского полуострова. Апатиты: Изд. Кольского филиала АН СССР. 1980. С. 88-92.

3. Балабонин Н.Л., Волошин А.В., Пахомовский Я.А., Поляков К.И. Состав джерфишерита из щелочных комплексов Кольского полуострова // Минералогический журнал. 1980. Т. 2. № 1. С. 90-99.

4. Быкова Э.В. Сульфидная минерализация в магнетитовых рудах и карбонатитах Ковдорского месторождения // Минералогия и геохимия. Вып. 5. Л.: Изд. Ленинградского гос. университета. 1975. С. 11-16.

5. Кухаренко А.А., Булах А.Г., Багдасаров Э.А., Римская-Корсакова О.М., Нефедов Е.И., Ильинский Г.А., Сергеев А.С., Абакумова Н.Б. Каледонский комплекс ультраосновных, щелочных пород и карбонатитов Кольского полуострова и Северной Карелии. М.: Недра. 1965. 772 с.

6. CrysAlisPro, Agilent Technologies. Version 1.171.36.20 release 27-06-2012.

7. Alsen N. Roentgenographische Untersuchungen der Kristallstrukturen von Magnetkies, Breithauptit, Pentlandit, Millerit und verwandten Verbindungen // Geologiska Foereningens i Stockholm Foerhandlingar. 1925. V. 47. P 19-73

8. Koto K., Morimoto N., Gyobu A. The superstructure of the intermediate pyrrhotite. I. Partially disordered distribution of metal vacancy in the 6C type, $\mathrm{Fe}_{11} \mathrm{~S}_{12} / /$ Acta Crystallographica. 1975. B 31. P. 2759-2764.

9. De Villiers J. The composition and crystal structures of pyrrhotite: A common but poorly understood mineral. Proceedings of Mintek 75, Randburg, South Africa, 4-5 June 2005

10. Lilies D.C., Villiers J.P.R.D. Redetermination of the structure of 5C pyrrhotite at low temperature and at room temperature // American Mineralogist. 2012. V. 97. P. 257-261. 